\title{
تأثير الدقيق المركب على الصفات الحسية لبعض المخبوزات اليمنية
}

\author{
خالد ناصر حميد \\ قسم علوم الاغذية والتغذية- كلية الزراعة - جامعة صنعاء
}

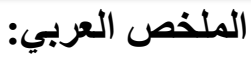

بهاف المساهمة في تقليص الفجوة الغذائية الكبيرة التي تتسع سنة بعد أخرى والناجمـة عن استيراد كميات كبيرة من

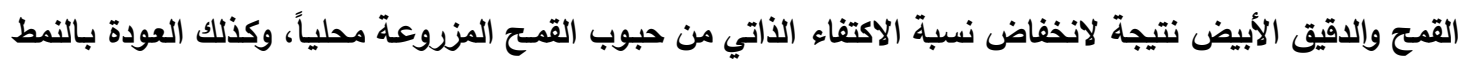

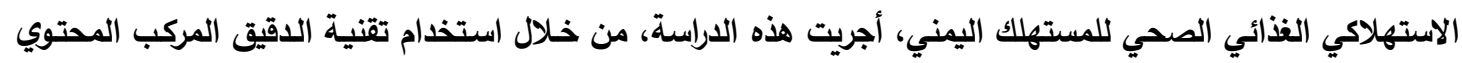
على دقيق بعض المحاصيل المحلية كالذرة الرفيعة والذرة الثـامية واللاخن والثعير، حيث تم التطرق إلى انتاج ثلاثة

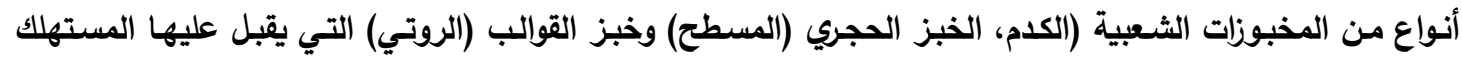

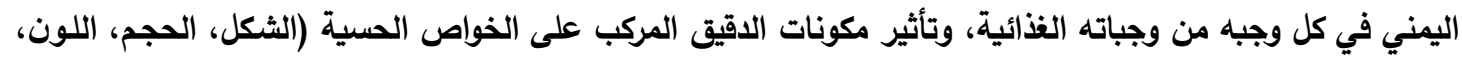

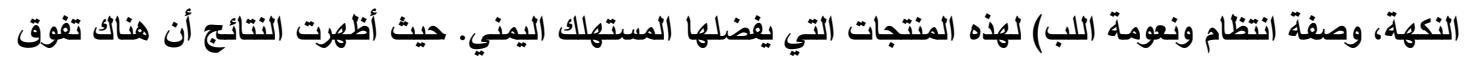

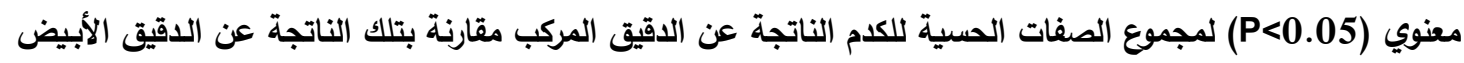

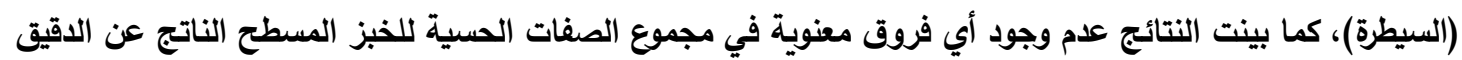
المركب والخبز المسطح الناتج عن الاقيق الأبيض (السبطرة)، من ناحية أخرى لم تختلف الصفات الحسية (الثكل،

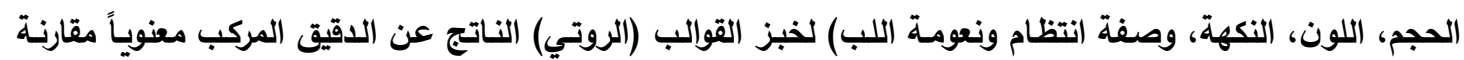

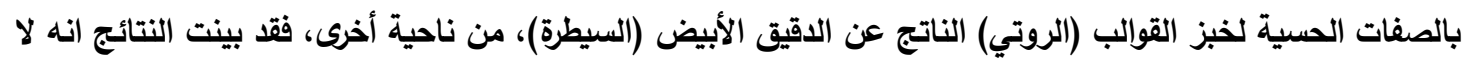

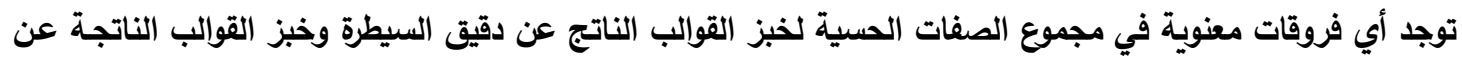

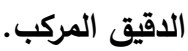

\section{الكلمات المفتاحية: الدقيق المركب، دقيق القدح، الخبز، الصفات الحسية}

\section{المقدمة}

احتياجاته اليومية لكل منهما على التوالي، وبالتالي كان

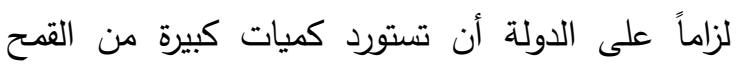

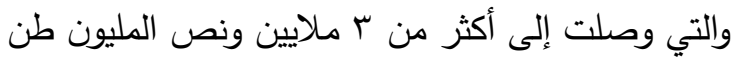

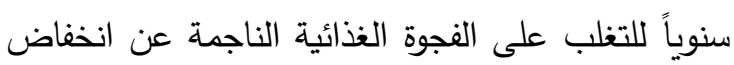

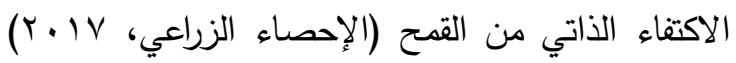
وربما يعود سبب ذلك إلى تغير نمط الاستهلاك الغذائي

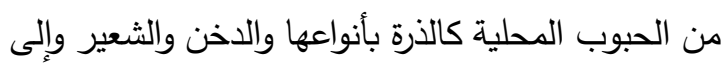
الاعتماد على القـح والدقيق الأبيض اللذان يستوردان بكميات كبيرة وبأسعار تستمر في الارتفاع سنة بعد الاعد لانيف

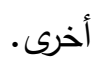

ازداد استهلاك الخبز بثكل مستمر في العديد من البلدان النامية بسبب تغير العادات الغذائية، وتزايد السكان بشكل مطرد وعليه فإن نسبة كبيرة من إجمالي

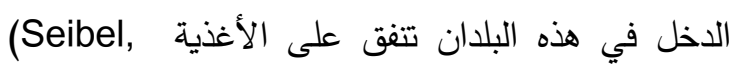
(2011، وهكذا زاد الاهتمام بالبحث عن الدقيق المركب

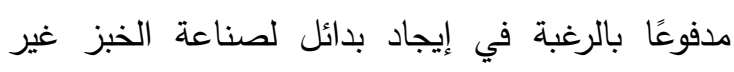
القدح من أجل تقليل اعتماد الدولة على القدح المستورد. يعتبر الخبز من أهم الوجبات الغذائية اليومية في اليمن

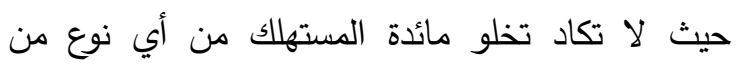
المخبوزات، حيث يعتبر الخبز المصدر الرئيسي للطاقة

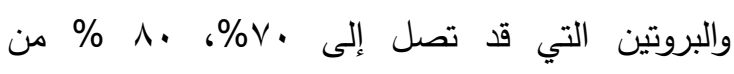


يعرف الدقيق المركب بأنه خليط من الدقيق والنشويات والمكونات الأخرى التي تهدف إلى استبدال دقيق القدح كليًا أو جزئًا في المخابز ومنتجات المعجنات، كما أكد (Shittu et al. 2007) إما خليط ثنائي أو ثلاثي من دقيق بعض المحاصيل مع دقيق القهح أو بدونه. تعتبر منتجات المخابز الناتجة عن الدقيق المركب ذات بدونه

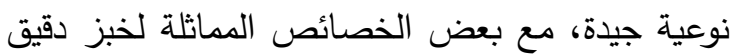

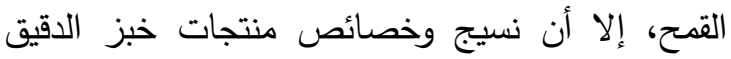
المركب تختلف قليلاً عن تلك المصنوعة من دقيق القدح فقط، مع زيادة القيمة الغذائية، حيث أن بروتينات القدح

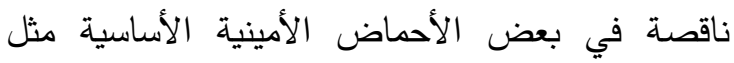
اللايسين والثريونين، ولذلك فإن تدعيم دقيق القـح بمواد غذائية غير مكلفة، مثل الحبوب والبقوليات الأخرى، يساعد على تحسين الجودة الغذائية للنتجات الدقيق المركب من خلال توفير توازنًا أفضل للأحماض الأمينية

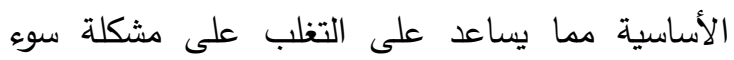
التغذية (Nilufer et al., 2008) يعد القدح مكونًا أساسيًا في العديد من أنواع الدقيق

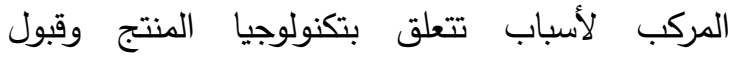
المستهلك، كما أن النسبة المئوية لدقيق القيح المطلوبة لتحقيق تأثير معين في الدقيق المركب تعتمد بشكل كبير على جودة وكمية جلوتين القدح وطبيعة المنتج المعني

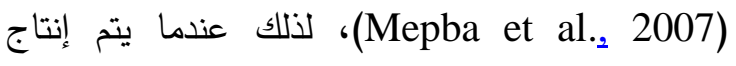
منتجات الخبز والمعجنات باستخدام الدقيق المركب، يجب أن تكون جودتها مماثلة قدر الإمكان لجودة المنتجات المصنوعة من دقيق القهح. لابد من التدرج في نسبة الإحلال بشكل تدريجي حتى دئ لتئ

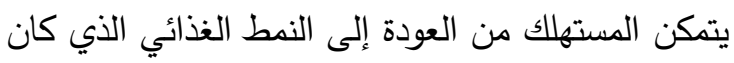

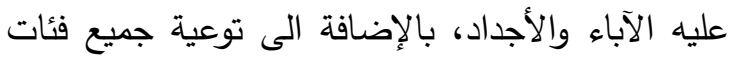

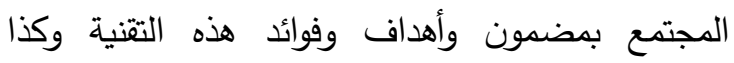
تشجيع المزارعين على المزيد من الإنتاج. الأخذ بتقانة

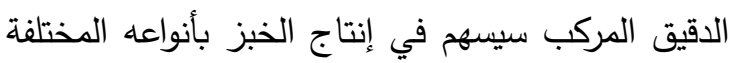

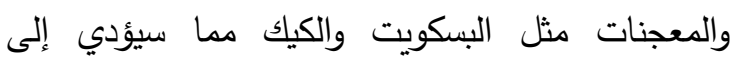

ان استخدام الدقيق المركب سيساهم في تحقيق العديد من الفوائد أهمها المساهمة في تقليص الفجوة الغذائية والتخفيف من فاتورة استيراد القصح وإحلال نسبة من المنتج المحلي في صناعة الخبز ومنتجاته وتحسين جودة الخبز الغذائية والصحية المقدم للمستهلك وكذا نشر الوعي الاستهلاكي للمواطنين بما يؤدي إلى تعديل النمط الاستهلاكي السائد للدقيق الأبيض. تعتبر تقنية الدقيق المركب مهمة بسبب ميزة تقليل المبلغ

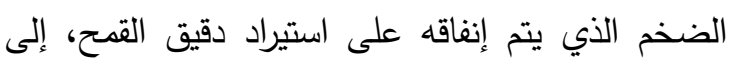
جانب احتمالات الاستفادة من المحاصيل غير المستغلة

(Peter-lkechukwu et al., 2019) من هنا وضعت الدولة بعض المعالجات النسبية لهذه المشكلة من خلال الأخذ بمخرجات نتائج البحوث

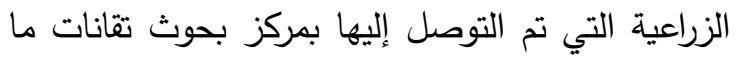

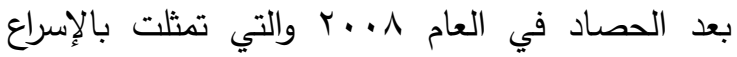
بالأخذ بالبدائل الممكنة للقدح كتقانة الدقيق المركب لإنتاج أنواع مختلفة من المخبوزات التي تتميز منتجاتها بقيمة غذائية عالية لاحتوائها على مجموعة كبيرة من الفيتامينات والألياف الغذائية ونسبة عالية من الأملاح والمعادن التي تساعد على الهضم وخفض امتصاص مله الدهون وحماية القولون من الإصابة بالسرطان، بالإضافة إلى وجود مواد فينولية ومواد مضادة للتأكسد (Noorfarahzilah, 2014)، وكل ذلكود سيؤدي إلى ولى تحسين المستوى الصحي للمستهلك من جهة، وتقليص حجم الفجوة الغذائية وتثجيع المزارعين لإنتاج الأنواع المختلفة من الحبوب الغذائية عالية الغلة كالذرة الرفيعة والثامية والدخن المرتفعة بقيمتها الغذائية كالبروتين من

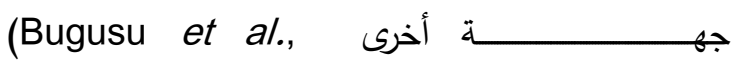
.2001., (Hasmadi et al., 2014) المكونات المستخدمة في الدقيق المركب على توافر المواد الخام في البلد المعني (Olaoy, et al., ) 2007. يعتبر الدقيق المركب مفيدًا في البلدان النامية لأنه يقلل من استيراد دقيق القمح ويشجع على استخدام المحاصيل الغذائية المزروعة محليًا كدقيق ( Ajatta, et .(al., 2016 


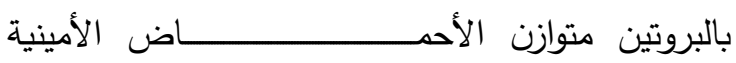

(Bojňanská et al., 2012., Mohammed et al.,

أهم خصائص بروتينات البقوليات هو محتواها العالي من اللايسين، الأحماض الأمينية الأساسية، مما يجعلها

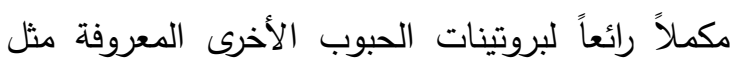
القمح الفقير في اللايسين، وقد أكد العديد من الباحثين امكانية استخدام البقوليات كعوامل غنية بالبروتين للمنتجات المخبوزة بثكل دقيق البروتين، مثل بروتين فول الصويا (Ribotta et al., 2005)، ودقيق الحمص بلنيف

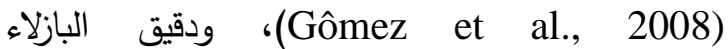
(Doxastakis et al., 2002.; Pollard et al., 2002).

أصبحت المنتجات المحتوية على الدخن مثل الذنن الاصبعي، الدخن اللؤلؤي، ودخن ذيل الثعلب شائعة

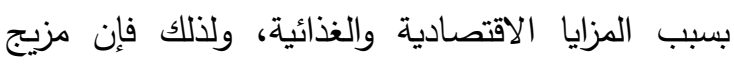

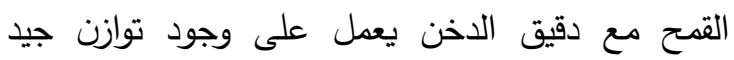

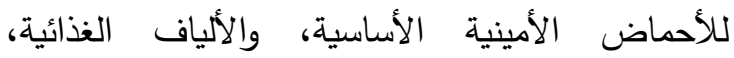
مضادات الأكسدة والمحتوى المعدني العالي مقارنة الألية

بالقصح.(Priyanka Tangariya., et all., 2018) الخبز المصنوع من دقيق الثعير يعتبر أيضًا الأكثر

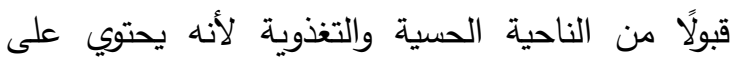
كميات ملحوظة من البروتين وإجمالي اللايسين والألياف

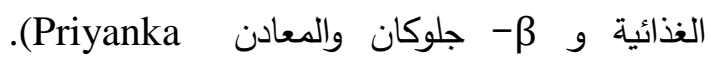
Tangariya., et al., 2018).;

لذلك هدفت هذه الدراسة انتاج بعض المخبوزات الثعبية

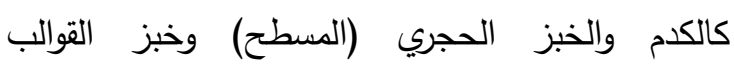
(الروتي) ومعرفة تأثير الديق المركب على الصفات الحسية لهذه المنتجات ومدى تقبل المستهلك لها.
تقليص الاستيراد من القصح والدقيق بنسبة قد تصل إلى .\% r هناك اتجاه كبير نحو استخدام الدقيق المركب من خلال احلال جزئي لاقيق المحاصيل المنتجة محليا، والبذور الئن عالية البروتين محل جزء من دقيق القصح لاستخدامه في المخبوزات المختلفة (Mepba et al.,2007). على الرغم من وجود جها كبير حاليًا لتحسين تقنية الخبز المركب، إلا أن بعض أنواع الخبز لا يزال يتطلب لئل r r .

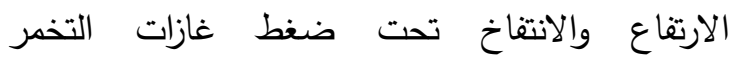
.(Olaoye et al.,2006) بثكل عام، يعد الدقيق المركب نهجًا جديدًا لإنتاج

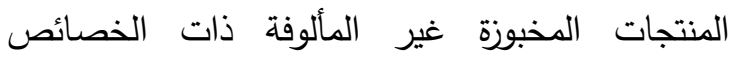

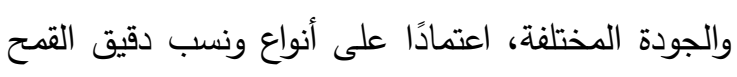

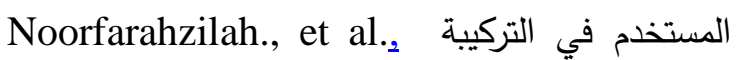
ان اضافة وخلط الدقيق المركب مع دقيق القدح لإنتاج

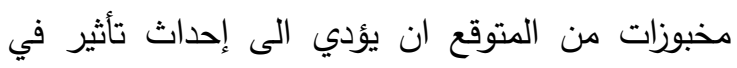
الخصائص الوظيفية للعينات المخلوطة. اجريت دراسة التئ الخصائص الوظيفية للدقيق المركب في معظم البلدان

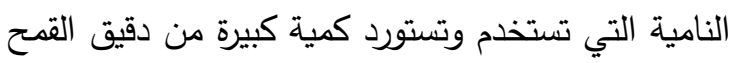
لتلبية العدد المتزايد من المستهلكين حيث ارتفاع الطلب كني

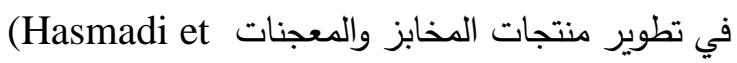
.al., 2020)

يعتبر دقيق الذرة الرفيعة بأصنافها الذختلفة والذرة الثامية والثعير والدخن من أكثر أنواع المحاصيل

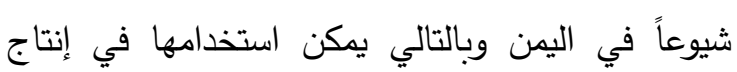
الدقيق المركب، كما يمكن استخدام بروتينات البقوليات

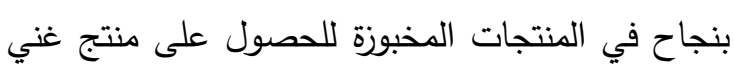


تمت عملية الخبازة والتقويم الحسي للمنتجات المواد والطرق المخبوزة في مخابز قوات النجدة، وبعض المخابز المواد المستخدمة الثعبية بالتعاون مع الإدارة العامة للإرشاد الزراعي ولئي

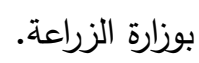

\section{تحضير العينات المخبوزة :} أولاً: الكدم: تحفيز العينات

تم تحضير الدقيق المركب الخاص بالكدم من خلال استبدال • ج \% من دقيق القدح بدقيق الدحاصيل

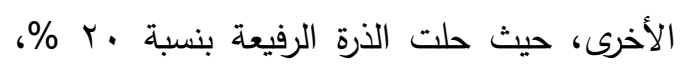

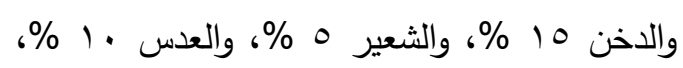

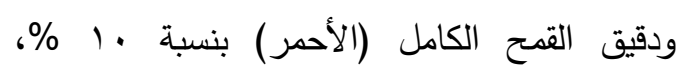
بالإضافة إلى عينة السيطرة التي تحتوي على دقيق القمح الأبيض فقط.

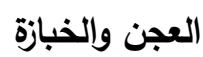

ا. دقيق القمح ماركة السنابل: تم الحصول عليه من السوق المحلية. r. دقيق الذرة الرفيعة Sorghum bicolor، دقيق الذه الذرة الثامية، دقيق الثعير، دقيق الاخن، ودقيق العدس تم الحصول عليها من السوق المحلية بأمانة

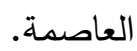
r. الدهن: سمن القهرية، من محلات بيع التجزئة بأمانة العاصمة صنعاء، من انتاج الثركة اليمنية

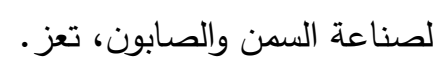
ץ.الخميرة: استخدمت خميرة سريعة الذوبان من فن فئن محلات بيع التجزئة بالعاصمة صنعاء.

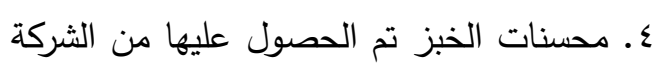
اليمنية للمطاحن وصوامع الغلال، عدن. ه. السكر والملح: تم شرائهما من السوق المحلية

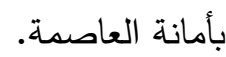

الجدول رقم (1) نسب ومكونات عجينة الكدم:

\begin{tabular}{|c|c|c|}
\hline لتحضير ه كيلوجرام & النسبة & المواد \\
\hline ..... جم (r كيلو) & $\% \varepsilon$ & دقيق القهح \\
\hline .... & $\%$ r. & دقيق الذرة الرفيعة \\
\hline ل V0. & $\% 10$ & دقيق الدخن \\
\hline 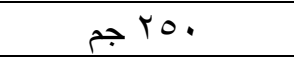 & $\% 0$ & دقيق الشعير \\
\hline ل. & $\% 1$. & دقيق القـح الكامل \\
\hline ل. & $\% 1$. & دقيق العدس \\
\hline TY.O & $\% 1$. ro & الخميرة \\
\hline & $\% 1$. ro & محسن خبز \\
\hline 0. & $\% 1$ & الدهون \\
\hline 0. & $\% 1$ & السكر \\
\hline 0. & $\% 1$ & الملح \\
\hline \multicolumn{2}{|c|}{ حسب الحاجة } & ماء \\
\hline
\end{tabular}

الخبازة حتى نضجت ومن ثم أُخرجت من الفرن ويُردت وتمت عملية التقويم الحسي. ثانياً: الخبز المسطح (الحجري): تم تحضير الدقيق المركب الخاص بالخبز المسطح

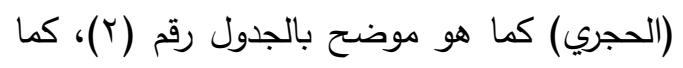
تم تحضير عينة السيطرة التي تحتوي على ل.. \% دقيق القدح الأبيض فقط.
استخدمت طريقة المرحلة الواحدة المتبعة في ماء

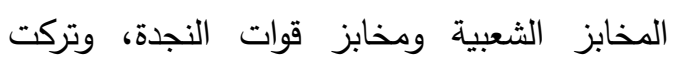
العجينة للتخمير لمدة ساعة واحدة تقريباً، بعدها قطعت العجينة الى قطع متساوية وبوزن حوالي

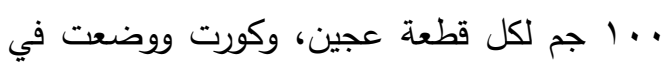

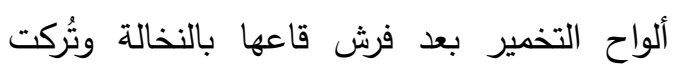
للتخمير النهائي بحدود ساعة أخرى، بعدها تم نقلها

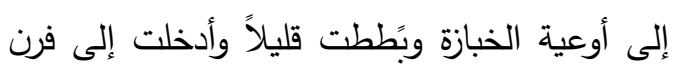




\begin{tabular}{|c|c|c|}
\hline لتحضير • كيلوجرام & النسبة & المواد \\
\hline$\varepsilon . \cdots$ & $\% \wedge$. & دقيق القــح \\
\hline$\because$ YO. & $\%$ & دقيق الشعير \\
\hline$\because$ YO. & $\%$ & دقيق الذرة الرفيعة \\
\hline$\because Y O$ & $\%$ & دقيق الدخن \\
\hline$\because Y O$ & $\% 0$ & دقيق الذرة الشامية \\
\hline $7 r .0$ & $\% 1 . r 0$ & خميرة \\
\hline 0. & $\% 1$ & سمن \\
\hline ס. & $\% 1 . r 0$ & محسن خبز \\
\hline 0. & $\% 1$ & سكر \\
\hline 0. & $\% 1$ & ملح \\
\hline \multicolumn{2}{|c|}{ حسب الحاجة } & 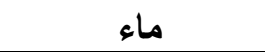 \\
\hline
\end{tabular}

الخبازة حتى نضجت ومن ثم أَخرجت من الفرن

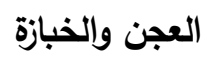
وبُردت وتمت عملية التقويم الحسي.

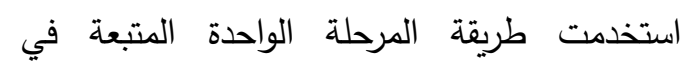

$$
\text { ثالثاً خبز القوالب (الروتي) }
$$
المخابز الثعبية ومخابز قوات النجدة، وتركت تم تحضير الدقيق المركب الخاص بخبز القوالب العجينة للتخمير لمدة ساعة واحدة تقريباً، بعدها (الروتي) من خلال استبدال 10 \% من دقيق القدح قطعت العجينة الى قطع متساوية وبوزن حوالي

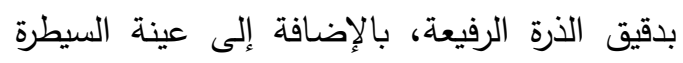

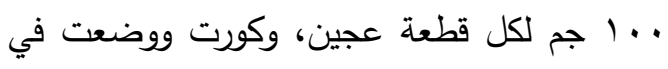

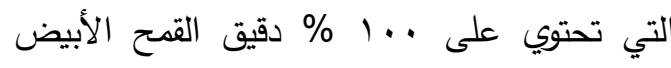
ألواح التخمير بعد فرش قاعها بالنخالة وتُركت

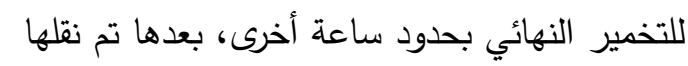
فقط.

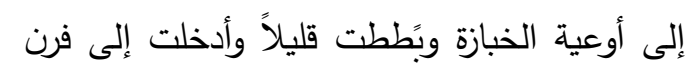

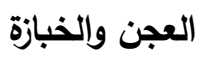

الجدول رقم (r) نسب ومكونات عجينة خبز القوالب (الروتي)

\begin{tabular}{|c|c|c|}
\hline لتحضير (ه كيلوجرام) & النسبة & المواد \\
\hline ร. Yo. & $\% \wedge 0$ & دقيق القمح \\
\hline Vo. & $\% 10$ & دقيق الذرة الرفيعة \\
\hline 74.0 & $\% 1$. ro & خميرة \\
\hline ס & $\% 1$. ro & محسن خبز \\
\hline 0. & $\% 1$ & سمن \\
\hline 0. & $\% 1$ & سكر \\
\hline 0. & $\% 1$ & ملح \\
\hline \multicolumn{3}{|c|}{ الماء حسب الحاجة } \\
\hline
\end{tabular}

تم خلط جميع المكونات وعجنت تماماً وترك العجين للتخمير في مكان دافئ لمدة • ب دقيقة.

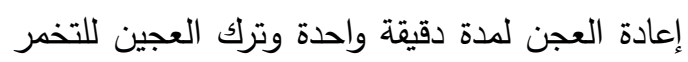
مرة أخرى لمدة · · دقيقة.
طريقة التحضير: تمت عملية الخبازة بطريقة المرحلة الواحدة طبقاً لما هو متبع في المخابز الثعبية كما يلي: 
خلال مجموعة من منتسبي النجدة والإدارة العامة للإرشاد الزراعي لتقويم جودة واستساغة المخبوزات

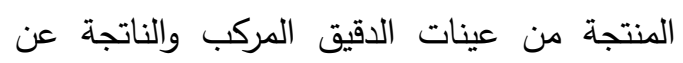

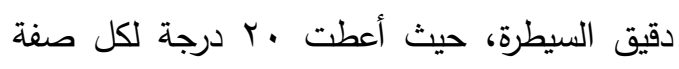

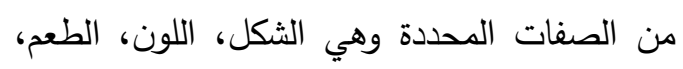
النكهة، النسجة الداخلية، والقبول العام (مجموع الصفات الحسية) قرين كل منتج.

\section{التحليل الإحصائي}

اجري التحليل الإحصائي وفقاً للتصميم تام التعشية ضمن Complete randomized design SAS, التجارب العاملية وباستخدام برنامج 1995 في تحليل البيانات، قورنت المتوسطات باختبار اقل فرق معنوي L.S.D واختبار دانكن Duncan عند فيطن مستوى معنوية (P>0.05).
قطعت العجينة إلى قطع صغيرة حسب حجم القالب وكور شكل العجين يدوياً حسب حجم القالب.

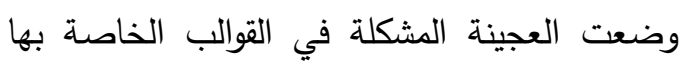
والمدهونة دهناً خفيفاً. تركت القوالب للتخمير النهائي في مكان دافئ لمدة •

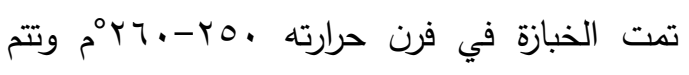
عملية الخبازة بفترة 10-ب بـ دقيقة أو ظهور اللون

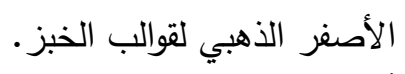
أُخرجت القوالب من الفرن وبردت وتمت عملية التقويم الحسي. اختبارات التقويم الحسي للمخبوزات تم التقويم الحسي لنماذج المخبوزات الثلاثة (الكدم، الخبز الحجري (المسطح) وخبز القوالب (الروتي)

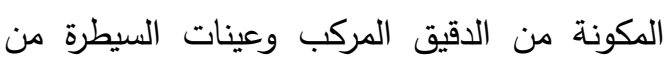

النتائج والمناقشة

التقويم الحسي للكدم

جدول (؛): الصفات الحسية للكدم الناتج من عينة الدقيق المركب قيد الدراسة

\begin{tabular}{|c|c|c|}
\hline الدقيق المركب & السيطرة & الصفة الحسية \\
\hline $11^{a}$ & $16^{b}$ & الثكل · r r \% \\
\hline $19^{a}$ & $14^{b}$ & 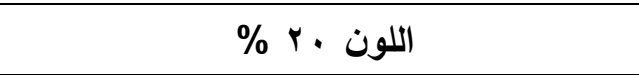 \\
\hline $19^{a}$ & $15^{b}$ & الطعم · r \% \\
\hline $19^{a}$ & $15^{b}$ & ا النكهة · r \% \\
\hline $19^{\mathrm{a}}$ & $13^{b}$ & 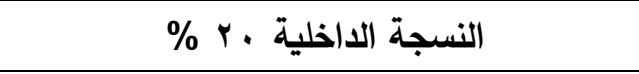 \\
\hline $9^{\mathrm{a}}$ & $73^{b}$ & القبول العام (مجموع الصفات الحسية) . . 1\% \\
\hline
\end{tabular}

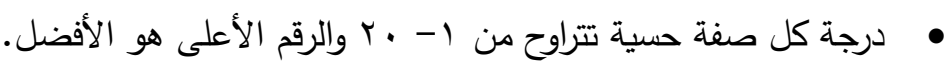

بتلك القيمة الخاصة بالكدم الناتجة عن دقيق القصح

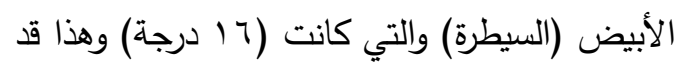
يرجع إلى أن المستهلك اليمني اعتاد على الثكل الحقيقي للكدم الناتجة عن الدقيق المركب الناتج عن خلط أنواع كثيرة من الحبوب، في حين أن

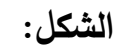
يتضح من خلال البيانات الموضحة في الجدول (ع) أن قيم متوسط انتظام الثكل للكدم الناتجة عن لئن الاقيق المركب كانت متفوقة معنويا (P>0.05) من قبل المقومين، حيث سجلت (1 ا درجة) مقارنة 
ينتفخ بالغازات الناتجة عن التخمر وهذا يتفق مع ما أشار اليه (Mepba et al., 2007) وهو مالم

يعتاد عليه المستهلك اليمني.

سجلت نكهة الكدم الناتجة عن الاقيق السيطرة (10 درجة)، وهذا التفوق المعنوي في هذه الصفة تشير إلى تفضيل المستهلكين لنكهة كدم الدقيق المركب التي تساهم بها مكونات الدقيق المركب المختلفة

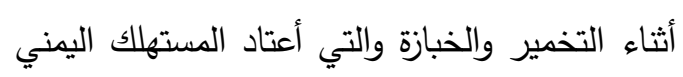
عليها، في حين انخفضت هذه الدرجة في الكدم الناتجة عن دقيق السيطرة والتي كانت ذات نكهة مشابهة لنكهة القوالب (الروتي)، وهذا يتقق مع ماتئن وجده (Olaoye et al., 2006).

\section{النسجة الداخلية:}

النتائج الموضحة في الجدول (ع) تشير إلى وجود

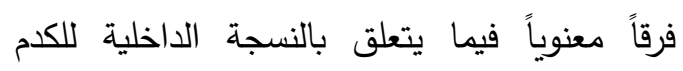

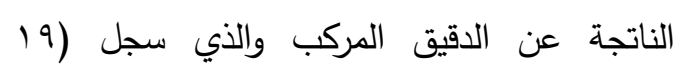
درجة) مقابل (با درجة) للكدم الناتجة عن دقيق

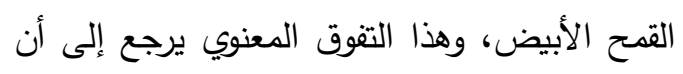
النسجة الداخلية لكدم الدقيق المركب تكون ممتلئة

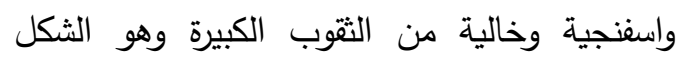

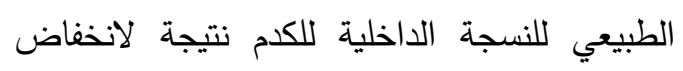
كمية بروتينات الجلوتين في دقيق الحبوب الداخلة

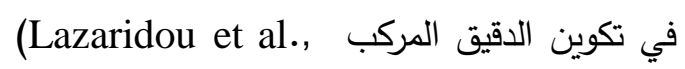
(2007، في حين أن النسجة الداخلية لكدم الدقيق

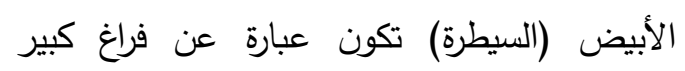
محتوياً على كمية قليلة من اللب الناتج عن انتفاخ

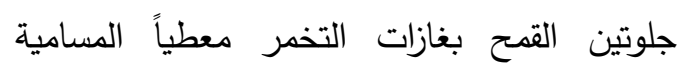

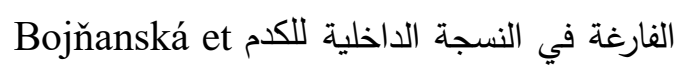
.(al.,2012)

مجموع الصفات الحسية (القبول العام)

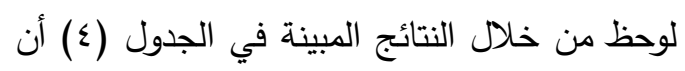

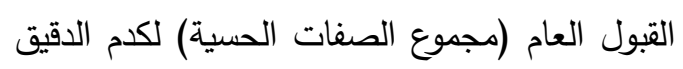

الكدم الناتجة عن الدقيق الأبيض ذو نسبة الاستخلاص المنخفضة تكون منتفة وفارغة من الاند الداخل وذات شكل غير مستحب نتيجة احتواء عجينة القهح الأبيض على بروتين الجلوتين الذي

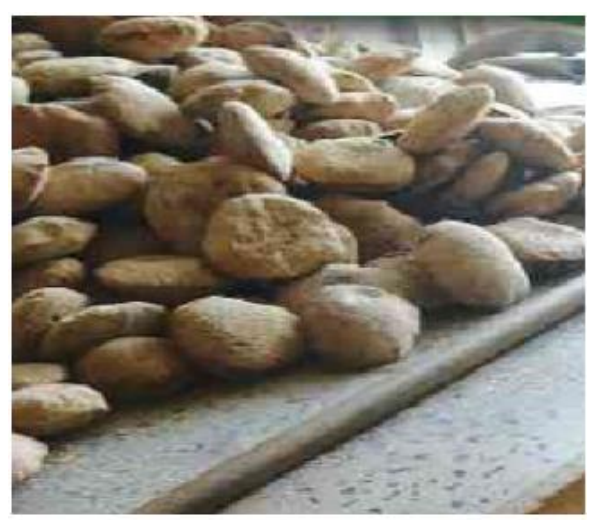

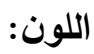

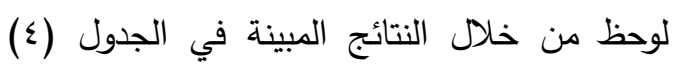
وجود فروقات معنوية (P>0.05) وتفوق كبير لخاصية اللون في الكدم الناتجة عن الدقيق المركب

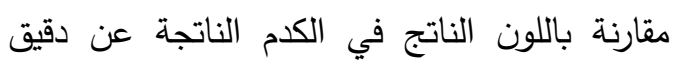
السيطرة، حيث سجل لون الكدم الناتجة عن الدقيق لعاته المركب (9 19 درجة)، في حين سجل دقيق السيطرة

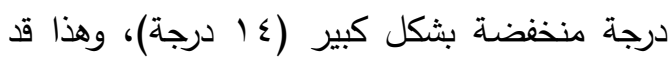
يرجع بشكل رئيسي إلى أن لون كدم الدقيق المركب

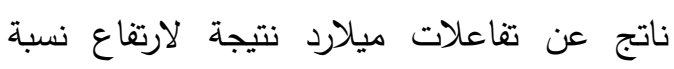
الأحماض الأمينية والسكريات المختزلة المتواجدة

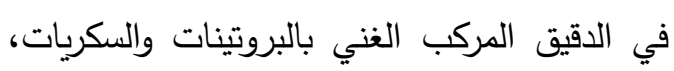
مقارنة بالنسبة المنخفضة منها في دقيق السيطرة، وهذا يتفق مع (Nilufer et al., 2008)، وكل فيلن فئل ذلك ساهم في تفضيل المستهلك للون كدم الدقيق المركب الذي أعتاد عليه المستهلك اليمني.

النكهة: يثير النتائج المذكورة في الجدول (ع) إلى أن هناك تفوق معنوي (0.05 > p) كبير لصفة نكهة الكدم الناتجة عن الدقيق المركب مقارنة بنكهة الكدم الناتجة عن دقيق السيطرة، حيث سجلت نكهة الكدم الناتجة عن الدقيق المركب (19 درجة)، في حين 
وهذا يؤكد أن الكدم الناتجة عن الدقيق المركب هي

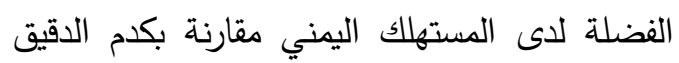
الأبيض (السيطرة).
المركب المفضلة لدى المستهلك قد تفوقت تفوقاً

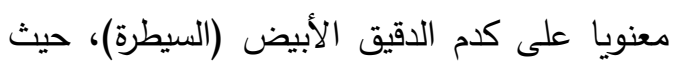

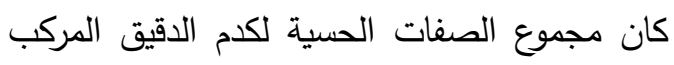
(T \% \% مقابل ( V \% \% ) لكدم الدقيق الأبيض،

التقويم الحسي للخبز المسطح (الحجري)

جدول (0) نتائج اختبارات التقويم الحسي للخبز المسطح (الحجري) الناتج عن عينة الدقيق المركب.

\begin{tabular}{|c|c|c|}
\hline الاقيق المركب & السيطرة & الصفة الحسية \\
\hline $17^{b}$ & $19^{a}$ & الثكل · r \% \\
\hline $19^{a}$ & $18^{\mathrm{a}}$ & اللون · r r \% \\
\hline $19^{a}$ & $16^{b}$ & النكهة . r r \\
\hline $18^{\mathrm{a}}$ & $16^{b}$ & صفات المضغ . r \% \\
\hline $16^{b}$ & $19^{a}$ & النسجة الاخلية . r \% \\
\hline $89^{a}$ & $88^{a}$ & المجموع . . 1 1 \\
\hline
\end{tabular}

كل رقم في الجدول يمثل معدل لثلاثة مكررات.

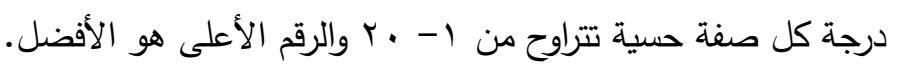

لبروتينات الجلوتين المتواجدة في الدقيق المركب نتيجة لانعدام بروتينات الجلوتين في دونين المحاصيل التي اشتركت مع دقيق القصح في تكوين الاقيق المركب مما أدى إلى تخفيف لبروتينات

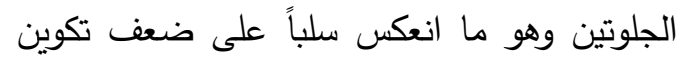
شبكة جلوتين غير قادرة على حجز غازات التخمر وبالتالي انخفاض القدرة على انتفاخ العجينة أثناء الخبازة وهذه تعتبر صفة غير مرغوبة لاى

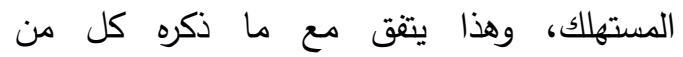
(Alhebeil et al., 2020)

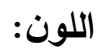

تثير النتائج الموضحة في الجدول (0) إلى أن

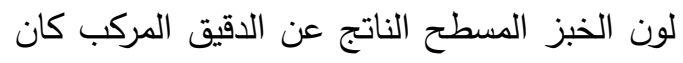

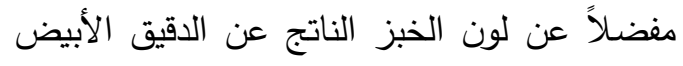

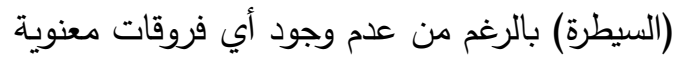
لهذه الخاصية، حيث سجل لون الخبز المسطح الناتج عن كل منهما (9 (، 11 (1 درجة)
يتضح من خلال بيانات الجدول (0) تفوق الخبز

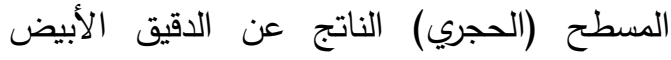
(السيطرة) معنوياً في قيم متوسطات الثكل مقارنة بنفس الصفة الخاصة بخبز الاقيق المركب، وهذا يرجع إلى أن صفة انتفاخ قطعة الخبز أثناء الخبازة صفة مرغوبة لدى المستهلك وهو ما حدث في دقيق إن السيطرة نتيجة ارتفاع نسبة بروتينات الجلوتين التي تعمل على تكوين شبكة جلوتين قوية تمكنها من القدرة على الاحتفاظ بغازات التخمر واعطاء خبز لتعني كبير الحجم ومنتفخ، في حين حدث تخفيف

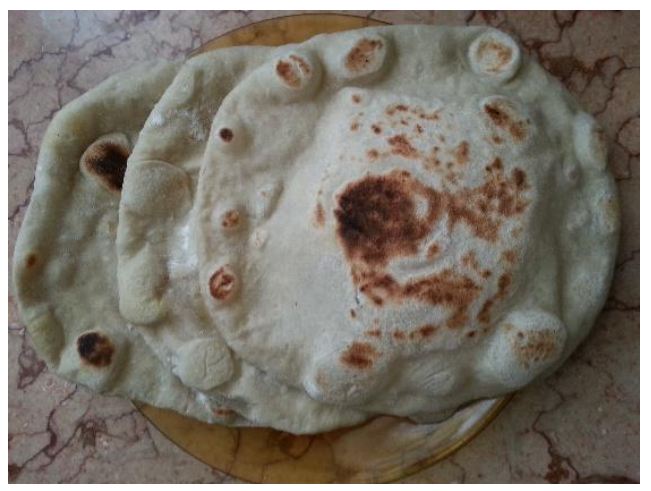


للدقيق السيطرة الذي سجل († ا درجة)، فقد فضل

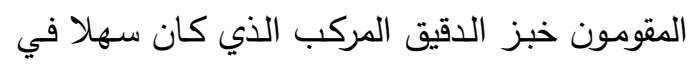

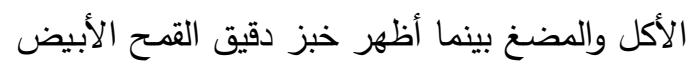
(السيطرة) صعوبة في التقطيع والمضـغ بالفم، وهذا

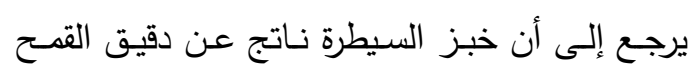
المرتفـع في محتـواه مـن بروتينـات الجلـوتين غيـر

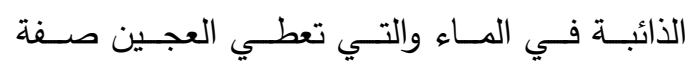

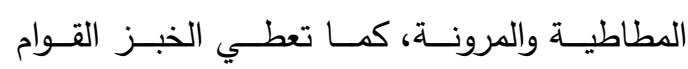

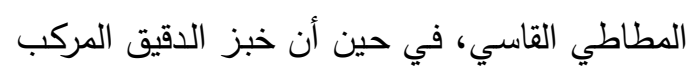

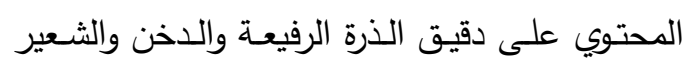

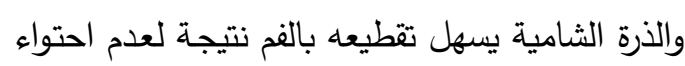

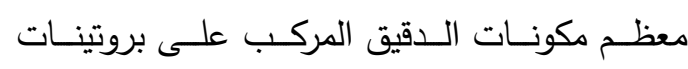

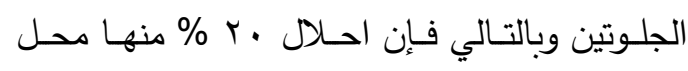

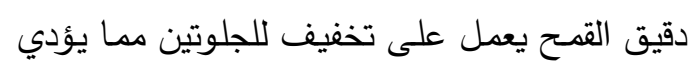
إلى انخفاض صفتي المطاطية والمرونة في عجينة وخبز الدقيق المركب، وبالتالي سهولة تقطيع ومضغ الخفي

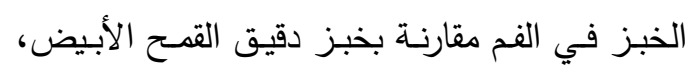

وهذا يتقق مع (Bojňanská et al., 2012).

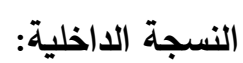

اظهرت النتائج الموضحة في الجدول (0) أن هناك

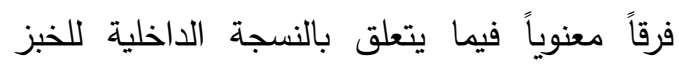

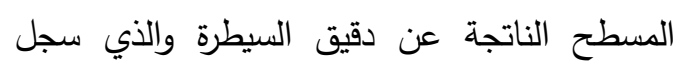
(9 19 درجة) مقابل (17 درجة) للخبز المسطح

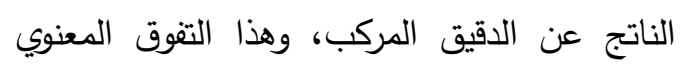
يرجع إلى أن النسجة الداخلية لخبز الدقيق السيطرة

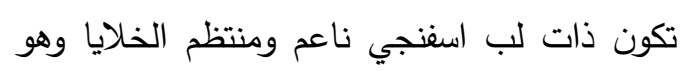
الثكل الطبيعي للنسجة الداخلية للخبز نتيجة للدور الحيوي الذي تلعبه شبكة الجلوتين المتواجدة بكثرة في دقيق القدح الأبيض والي يعطي الدقيق والخبز

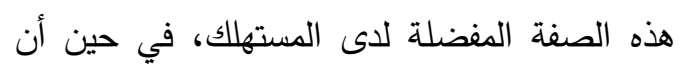

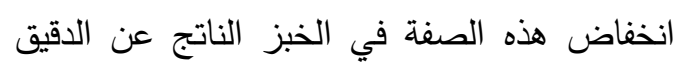
المركب الدحتوي على دقيق الذرة الرفيعة والدخن

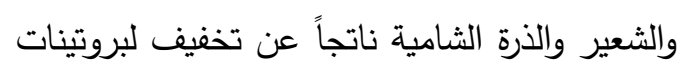
الجلوتين والتي تقتقر لها هذه الأنواع من الدقيق المركب مما انعكس سلباً على هذه الصفة المفضلة
على التوالي، وهذا قد يرجع بشكل رئيسي إلى أن لون الخبز المسطح الناتج عن الدقيق المركب لتبّل

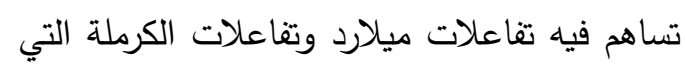
تحدث أثناء الخبازة نتيجة لارتفاع نسبة الأحماض الأمينية الأساسية والسكريات في دقيق الذرة الرفيعة

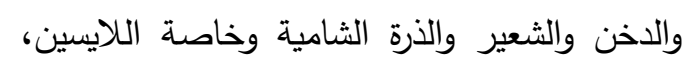

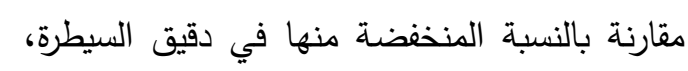

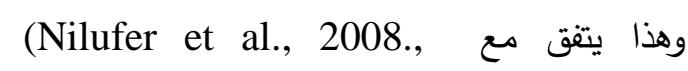

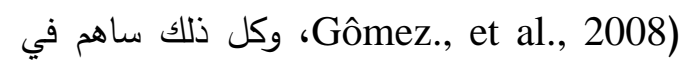
تفضيل المستهلك للون الخبز المسطح الناتج عن الهن الدقيق المركب الذي أعتاد عليه المستهلك اليمني.

\section{النكهة:}

من خلال النتائج المبينة في الجدول (0) يتضح أن

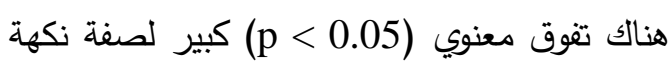
الخبز المسطح الناتجة عن الدقيق المركب مقارنة

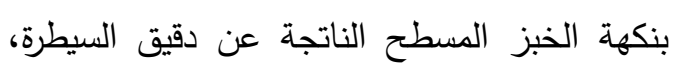

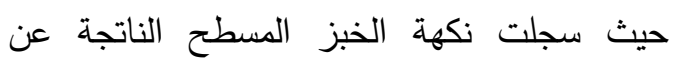
الدقيق المركب (9 (19 درجة)، في حين سجلت نكهة الخبز المسطح الناتجة عن الدقيق السيطرة (17) درجة)، وهذا التقوق المعنوي في هذه الصفة تثير

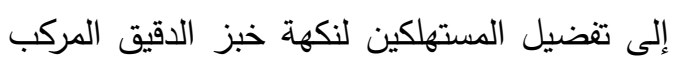
التي تساهم بها مكونات الدقيق المركب المختلفة

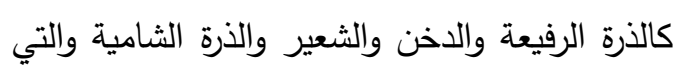

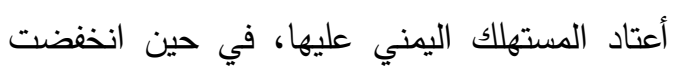
هذه الدرجة في الخبز المسطح الناتجة عن دقيق Olaoye et al., ) السيطرة وهذا يتفق مع ما وجدة لهن لهن .(2011 صفة المضغ: يثـير نتـائج الجـدول (0) إلـى أن هنـاك فروقـات

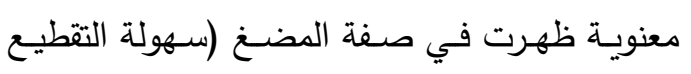

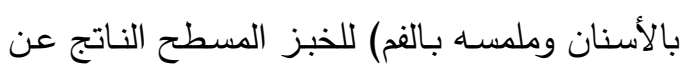

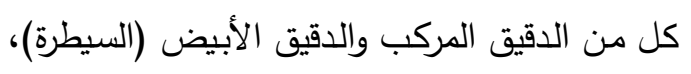

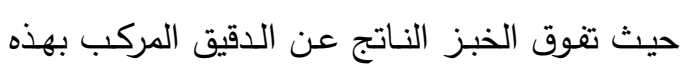

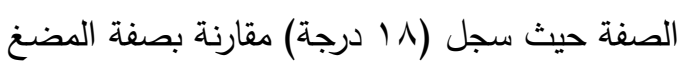




$$
\text { التظويم الحسي لخبز القوالب (الروتي) }
$$

تثير النتائج الموضحة في الجدول (T) الى عدم وجود فروق معنوية (0.05 >0 p) في صفة انتظام

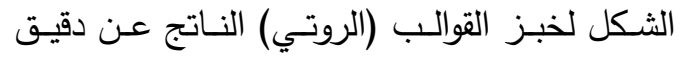
القـح الأبيض (السيطرة) وبين خبز القوالب الناتج عن الدقيق المركب المكون من 1 \% \% دقيق قمح ابيض و 10 \% دقيق الذرة الرفيعة حيث سجل كل منهما (9 ( درجة)، وهذا يدل على عدم تأثر الدقيق المركب بدقيق الذرة الرفيعـة عند هذه النسبة مـن الإحـلال وقدرة دقيق القــح على تحمل نسبة هـن

دقيق الذرة الرفيعة الخالية من بروتينات الجلوتين.
Bojňanská et ) لدى المستهلك وهذا يتفق مع .(al., 2012 مجموع الصفات الحسية: لوحظ من نتائج الجدول (0) عدم وجود أي فرق أهنئ معنوي في مجموع الصفات الحسية (القبول العام) للخبز المسطح (الحجري) الناتج عن الدقيق المركب والخبز المسطح الناتج عن الدقيق الأبيض (السيطرة)، حيث كان مجموع الصفات الحسية

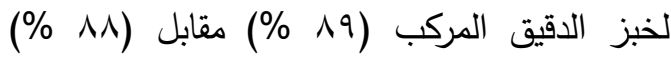
لخبز الدقيق الأبيض، وهذا يؤكد أن الخبز المسطح

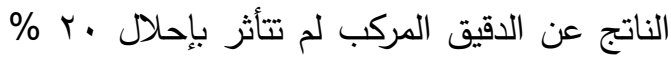

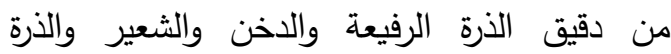
الثامية محل دقيق القهح من جهة، ومن جهة

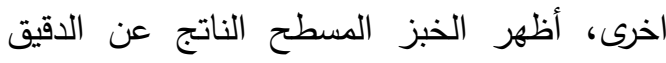
المركب قبولاً كبيراً لدى لجنة التحكيم.

\begin{tabular}{|c|c|c|c|}
\hline الدقيق المركب & السيطرة & درجة الأساس & الصفة الحسية \\
\hline $19^{a}$ & $19^{a}$ & $r$ r. & انتظام الشكل \\
\hline $18^{a}$ & $19^{a}$ & r. & الحجم \\
\hline $18^{a}$ & $18^{a}$ & $r$. & اللون \\
\hline $18^{a}$ & $18^{\mathrm{a}}$ & $r$ r. & النكهة \\
\hline $19^{a}$ & $19^{a}$ & $r$. & نعومة وإنتظام اللب \\
\hline $92^{a}$ & $93^{a}$ & $1 \ldots$ & المجموع \\
\hline
\end{tabular}

جدول (†) نتائج اختبارات التقويم الحسي لخبز القوالب الناتج عن عينة الدقيق المركب.

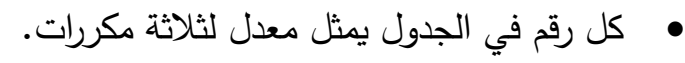

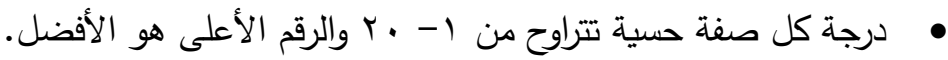

اظهرت النتائج المبينـة في الجدول (†) إلى عدم

وجود فرق معنوي (0.05 > p p ) في صفة حجم

خبز القوالب (الروتي) الناتج عن كل من دن دقيق السيطرة والدقيق المركب، بـالرغم من زيـادة حجم

خبز القوالب الناتج عن دقيق السيطرة مسجلا (19

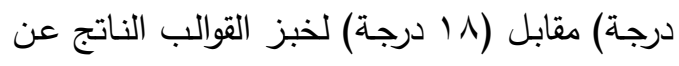

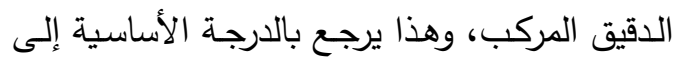

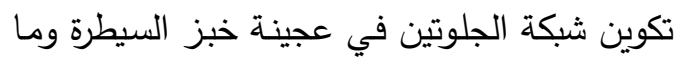

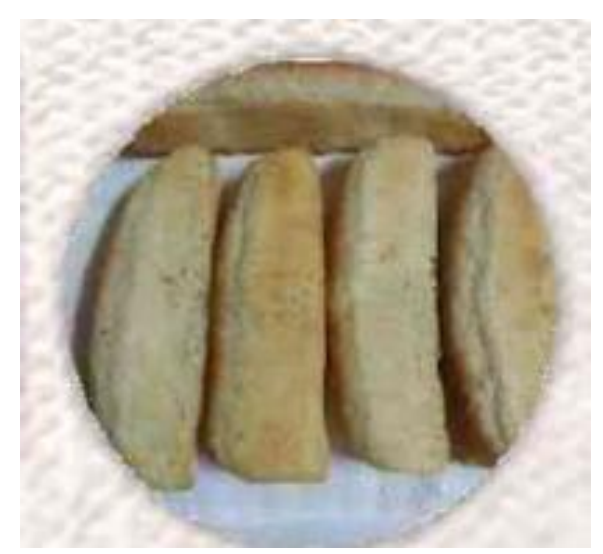


نعومة وانتظام اللب:

يشير الجدول (7) إلى عدم وجود فرقاً معنوياً فيما يتعلق بنعومة وانتظام اللب في خبز القوالب (الروتي) الناتج عن دقيق السيطرة وخبز القوالب (الروتي) الناتج عن الدقيق المركب والذي سجل (19 درجة لكل منهما)، حيث كان لب نوعي القوالب (الروتي) اسفنجيا ناعما وذات خلات خلايا منتظمة، وهذا هو الثكل الطبيعي للنسجة الداخلية للخبز نتيجة للدور الحيوي الذي تلعبه شبكة الديكة

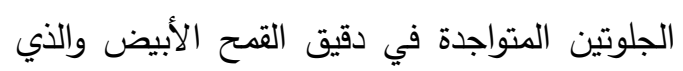

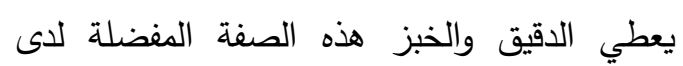
المستهلك، في حين أن هذه الصفة في الخبز الناتج

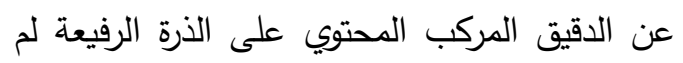

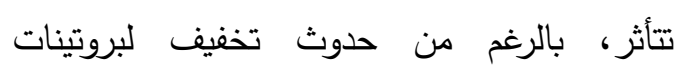
الجلوتين والتي يفتقر لها دقيق الذرة الرفيعة، وهذا

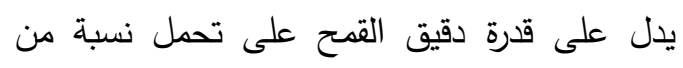
دقيق الذرة الرفيعة وربما لوجود محسنات الدقيق

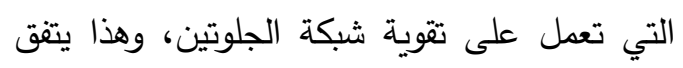
مع ما ذكره (Bojňanská et al.,2012).

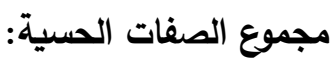

لوحظ من الجدول (T) عدم وجود أي فرق معنوي

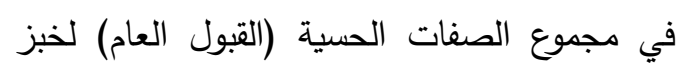
القوالب (الروتي) الناتج عن الدقيق السيطرة وخبز التبل

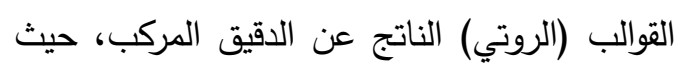
كان مجموع الصفات الحسية لخبز الدقيق السيطرة

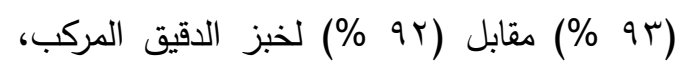
وهذا يؤكد أن خبز القوالب (الروتي) الناتج عن الدقيق المركب لم يتأثر بإحلال 10 \% من دوكال دقيق الذرة الرفيعة محل دقيق القدح، وقد حضي خبز بإلان

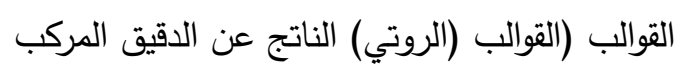
بقبول كبير لاى لجنة التحكيم. أما من الناحية الغذائية والصحية، فقد أثارت لفئل الكثير من الأبحاث إلى ارتفاع القيمة الغذائية

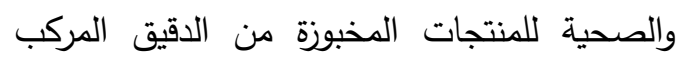

تمتاز به من مرونة ومطاطية والقدرة على الانتفاخ

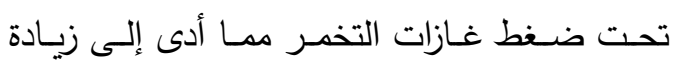

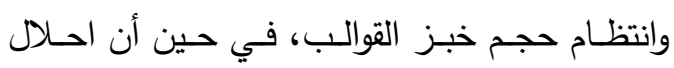
دقيق الذرة الرفيعة الفقيرة ببروتينات الجلوتين بنسبة

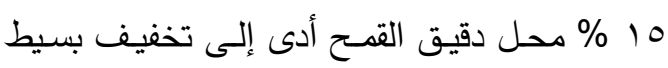

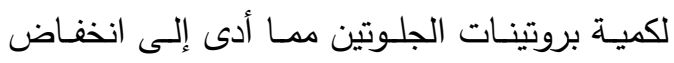
بسيط وغير معنوي في حجم خبز القوالب، وهذا

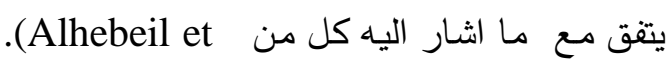
al., 2020)

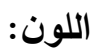
يشير النتائج الموضحة في الجدول (T) إلى عدم وجود أي فروقات معنوية (0.05 > p p) لخاصية اللون في خبز القوالب (الروتي) الناتج عن الدقيق

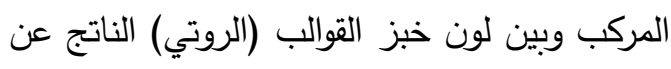
دقيق السيطرة، حيث سجل لون الخبز الناتج عن كل منهما (1/، 1/ درجة) على التوالي، وهذا قد يرجع بشكل رئيسي إلى عدم تأثر لون القوالب الب التوالي

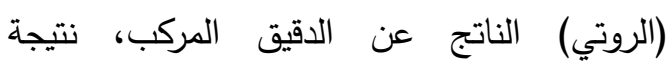
لإنخفاض نسبة الإحلال منها محل دقيق القدح

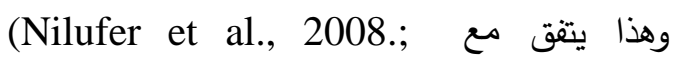

.Gômez et al., 2008)

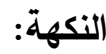

يلاحظ من خلال النتائج المبينة في الجدول (0) إلى عدم وجود أي فرق معنوي (0.05 )

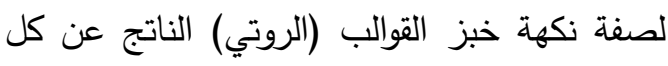
من الدقيق المركب ودقيق السيطرة، حيث سجلت نكهة خبز القوالب (الروتي) الناتجة عن كل منهما (1) 1 درجة)، وهذا يشير إلى عدم تأثر نكهة القوالب (الروتي) الناتج عن الدقيق المركب بإحلال نسبة 10 \% من دقيق الذرة الرفيعة محل دقيق القدح،

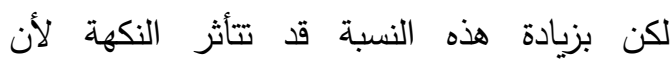
المستهلك اعتاد على تتاول خبز القوالب (الروتي) الناتج عن دقيق القـح فقط وهذا يتفق مع ما وجده .(Olaoye et al., 2006) 


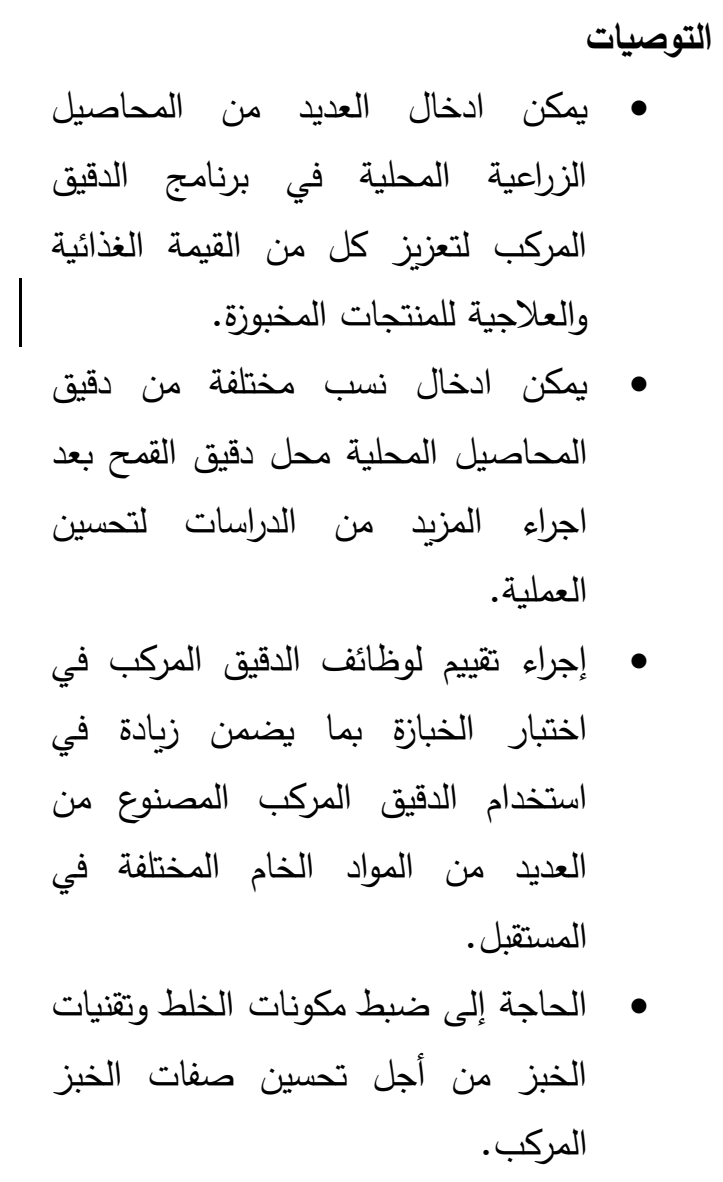

Aluge, O.; Akinola. S.A. and Osundahunsi, O. 2016. Effect of malted sorghum on quality characteristics of wheatsorghum-soybean flour for potential use in confectionaries. Food and Nutrition Sciences 7(13): $1241-\quad 1252$. https://doi.org/10.4236/fns.2016.71311 4

Bojňanská, T., Frančáková, H., Lišková, M. and Tokár, M. 2012. Legumes - the alternative raw materials for bread production. Journal of Microbiology, Biotechnology and Food Sciences 1: 876-886.

Bugusu, B., Campanella, O. and Hamaker, B. 2001. Improvement of sorghum-wheat composite dough rheological properties
مقارنة بالمنتجات المخبوزة من دقيق القمح منخفض الاستخلاص نتيجة للتكامل الغذائي في نوعية الأحماض الأمينية الأساسية بين مكونات الدقيق المركب، وارتفاع نسبة الألياف الغذائية والفيتامينات والأملاح المعدنية المختلفة في دقيق محاصيل (Noorfarahzilah et al., - الحبوب الأخرى 2014) الاستتتاجات من خلال هذه الدراسة يمكن الاستتتاج أن: استخدام تقنية الدقيق المركب تعتبر مفيدة في بلادنا، مما سيسهم في تقليص الفجوة الغذائية الناجمة عن استيراد القمح والدقيق من الخارج. امكانية استخدام العديد من دقيق دائ المحاصيل الغذائية المحلية جزئياً محل مل أل دقيق القمح بدون التأثير على الصفات الحسية المرغوبة من قبل المستهلك. • العودة التدريجية بالنمط الاستهلاكي

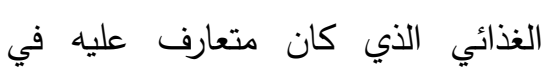

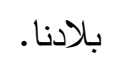

كتاب الإحصاء الزراعي. VIV P. الإدارة العامة للإحصاء والمعلومات الزراعية. وزارة الزراعة والري. الجمهورية اليمنية.

\section{References}

Ajatta, M.; Akinola, S. and Osundahunsi, O. 2016. Proximate, functional and pasting properties of composite flours made from wheat, breadfruit and cassava starch. Applied Tropical Agriculture 21(3): 158165.

Alhebeil, S.; Alhadi. N. and Shanibah, S 2020. Effect of partial substitutions with barley flour on rheological properties of white flour dough and bread produced. 19(2): 27-34 
Lazaridou, A., Duta, D., Papageorgiou, M., Belc, N. and Biliaderis, C.-2007. Effects of hydrocolloids on dough rheology and bread quality parameters in gluten free formulations. Journal of Food Engineering 79: 1033-1047.

Mepba, H., Eboh, L., Nwaojigwa, S. 2007. Chemical composition, functional and baking properties of wheat-plantain composite flour. African Journal of Food, Agriculture, Nutrition and Development, $7,22$.

Mohammed, I., Ahmed, A. and Senge, B. 2012. Dough rheology and bread quality of wheat-chickpea flour blends. Industrial Crops and Products 36: 196-202.

Nilufer, D., Boyacioglu, D. and Vodovotz, Y. 2008. Functionality of soymilk powder and its components in fresh soy bread. Journal of Food Science 73: 275- 281.

Noorfarahzilah, M., 1Lee, J. S., 1Sharifudin, M. S., 2Mohd Fadzelly, A. and Hasmadi, M. 2014. Applications of composite flour in development of food products. International Food Research Journal 21(6): 2061-2074.

Olaoye, O. A., \& Ade-Omowaye, B. I. O. 2011. Composite flours and breads: potential of local crops in developing countries. In V. R. Preedy, R. R. Watson, \& V.B. Patel, (Eds.), Flour and breads and their fortification in health and disease prevention (pp.183- 192). London, Burlington, San Diego: Academic Press,

Olaoye, O., Onilude, A. and Idowu, O. 2006. Quality characteristics of bread produced from composite flours of wheat, plantain and soybeans. African Journal of Biotechnology, 5, 1102e1106.

Olaoye, O. Onilude, A. and Oladoye, C. 2007. Breadfruit flour in biscuit making: and breadmaking quality through zein addition. Cereal Chemistry 78(1): 31-

Dhingra, S. and Jood, S. 2001. Organoleptic and nutritional evaluation of wheat breads supplemented with soybean and barley flour. Journal of Food Chemistry 77: 479-488.

Doxastakis, G., Zafiriadis, I., Irakli, M. and Tananaki, C. 2002. Lupin, soya and triticale addition to wheat flour

Giami, S., Amasisi, T., \& Ekiyor, G. 2004. Comparison of bread making properties of composite flour from kernels of roasted and boiled African breadfruit (Treculia africana Decne) seeds. Journal of Materials Research, 1, 16e25.

Gômez, M., Oliete, B., Rosell, C., Pando, V. and Fernandez, E. 2008. Studies on cake quality made of wheat chickpea flour blends. LWT-Food Science Technology 41: 1701-1709.

Hasmadi, M., Siti Faridah, A., Salwa, I., Matanjun, P., Abdul Hamid, M. and Rameli, A. 2014. The effect of seaweed composite flour on the textural properties of dough and bread. Journal of Applied Phycology 26:1057-1062.

Hasmadi, M.; Noorfarahzilah, M.; Noraidah, H.; Zainol, M. and Jahurul, M. 2020. Functional properties of composite flour: a review. Food Research 4 (6): 1820 1831.

Hugo, L., Rooney, L. W. and Taylor, J. .2000 . Malted sorghum as a functional ingredient in composite bread. Cereal Science 79(4): 428-432.

Jisha, S., Padmaja, G., Moorthy S. and Rajeshkumar, K. 2008. Pre-treatment effect on the nutritional and functional properties of selected cassava-based composite flours. Innovative Food Science and Emerging Technologies 9: 587-592. 
Food Resources and Technology 216: 50 .

Saeed, S., Muhammad, M; Humaira, K., Saima, P., Sharoon, M. and Abdus, S. 2012. Effect of sweet potato flour on quality of cookies. Journal Agriculture Resources 50(4).

Saha, S.; Gupta, A.; Singh, S.; Nidhi Bharti; K.; Singh, V.; Mahajan, and $\mathrm{H}$. Gupta. 2011. Compositional and varietal influence of finger millet flour on rheological properties of dough and quality of biscuit. LWT - Food Science and Technology, 44(3):616621.

Sharma, S., Bajwa, U., and Nagi, H. 1999. Rheological and baking properties of cowpea and wheat flour blends. Journal Science Food Agriculture 79: 657-662.

Shittu, T., Raji, A. and Sanni, L. 2007. Bread from composite cassava-wheat flour: I. Effect of baking time and temperature on some physical properties of bread loaf. Food Research International 40: 280290 .

Siebel, W. 2011. Future of flours. composite flours. Downloaded from www.muehlenchemie.de/ downloadsfuture-of-flours/fof_kap_16.pdf on 3/12/2011.
Effects on product quality. African Journal of Food and Science, 1, 20-23.

Peter-Ikechukwu, A.; Ibeabuchi, J.; Eluchie, C.; Agunwa, I. and Aneke, E. (2019). Functional properties of sausage rolls made from cocoyam and wheat flour enriched with soybean flour. Food Sci Nutr Stud 3(2): 39-53. http://doi.org/10.22158/fsns.v3n2p39

Pollard, N., Stoddard, F. Popineau, Y., Wrigley, C. and MacRitchie, F. 2002. Lupin flours as additives: dough mixing, breadmaking, emulsifying, and foaming. Cereal Chemistry 79: 662-669.

Priyanka T., Anushriya.; Pratima A.; and Anupama. P. 2018. Quality analysis of composite flour and its effectiveness for Chapatti formulation. Journal of Pharmacognosy and Phytochemistry 2018; 7(4): 1013-1019

Ribotta, P., Arnulphi, S., Leôn, A.; and Anôn, $M$.2005. Effect of soybean addition on the rheological properties and breadmaking quality of wheat flour. Journal Science Food Agriculture 85: 1889-1896.

Sadowska, J., Blaszczak, W., Fornal, J., Vidal-Valverde, C. and Frias, J. 2003. Changes of wheat dough and bread quality and structure as a result of germinated pea flour addition. European 


\title{
EFFECT OF COMPOSITE FLOUR ON SENSORY CHARACTERISTICS OF SOME YEMENI BAKED GOODS \\ Khaled Naser Naser Hemeed \\ Department of Food Sciences and Nutrition \\ Faculty of Agriculture - Sana'a University
}

Email: dr.jalal.fadhl@gmail.com

\begin{abstract}
This study aims contributing to reduce the large food gap that widens from year after year, caused by the import of large quantities of wheat and white flour as a result of the low selfsufficiency ratio of locally grown wheat grain, also aimed to return of the healthy food consumption pattern for Yemeni consumer, so this study was conducted using the composite flour technique and containing flour for some local crops, such as sorghum, corn, millet and barley. As this study examined the production of three types of popular baked (kodam, flat and roti bread), which the Yemeni consumer accepts for each of his meals, and the effect of compounds of the flour on the sensory characteristics (shape, size, color, flavor and pulp regularity and smoothness) of these products which prefer by the Yemeni consumer. The results showed that their significant superiority $(P<0.05)$ of the total sensory characteristics of the kodam produced by composite flour compared to that produced by the white flour (control). The results also showed that no significant differences for total sensory characteristics between flat bread produced by the composite flour and produced by the white flour (control), on the other hand, there is no significant differences for the sensory characteristics (shape, size, color, flavor and pulp regularity and smoothness) of the roti produced from the composite flour compared to the sensory characteristics of the roti produced from the white flour (control). On the other hand, there is no significant differences for the whole sensory characteristics of the roti produced from the white flour (control), compared to the roti produced from the composite flour.
\end{abstract}

key words:

Composite flour, wheat flour, bread, sensory characteristics. 